\title{
Kisa Rapor
}

\section{Şanlıurfa'da çalışan aile sağlığı elemanlarının iş doyum düzeyleri ve etkileyen faktörler}

\author{
Mehmet Enes Gökler a, Hasan Durmuş ${ }^{b}$
}

\begin{abstract}
a MD., Doktor Öğretim Görevlisi, Ankara Yıldırım Beyazıt Üniversitesi Halk Sağlı̆̆ı A.B.D. Ankara, Türkiye b MD., Halk Sağlığı Uzmanı, Kilis İl Sağlık Müdürlüğü, Kilis, Türkiye
\end{abstract}

\section{Öz}

Amaç: Çalışmada, Şanlıurfa ilinde hizmet veren aile sağlığı elemanlarının demografik özellikleri, hizmet sundukları nüfusun özellikleri, meslekleriyle ilgili düşünceleri, iş doyumları ve iş doyumu üzerine etkili olabilecek değişkenlerin tespiti amaçlanmıştır. Yöntem: Çalışma, Şanlıurfa'da görev yapan aile sağlığı elemanları üzerinde yapılan kesitsel tipte bir araştırmadır. Hesaplanan örneklem hacmine göre ilçe dağılımı ve kır-kent hizmet sunumu durumu göz önünde bulundurularak rasgele seçilen 150 aile sağlığı elemanına ulaşılması hedeflendi. Hazırlanan anket formu, aile sağlığı elemanlarının sosyo-demografik ve mesleki özelliklerini ve Minnesota iş doyum ölçeğini içermekteydi. Bulgular: Toplam 125 (\%83.3) aile sağlı̆̆ı elemanına ulaşıldı. Çalışmaya katılan aile sağlığı elemanlarının \%87.2'si kadın, \%28.8'i kırsalda hizmet vermekteydi. Çalışma grubunun genel, içsel ve dışsal iş doyum puan ortalamaları sirasıyla $3.05 \pm 0.74,2.79 \pm 0.79$ ve $3.23 \pm 0.79$ olarak bulundu. Aile sağlığı elemanlarının \%26.4'ünün iş doyumu yüksektir. Aile sağlığı merkezinde kalıcı olarak çalışmayı düşünme [OR: 3.25 (1.188.96)] ve genel olarak işinden memnun olma [OR: 4.46 (1.17-16.93)] iş doyumunun yüksek olmasında ilişkili faktörlerdir. Sonuç: Aile sağlığı elemanlarının iş doyumu düzeyleri düşüktür. Aile sağlığı elemanları birinci basamak sağlık hizmeti sunumun da önemli bir yere sahiptirler. İș doyumlarını arttıracak düzenlemelerin yapılması hizmetin kalitesini arttıracaktır.

Anahtar kelimeler: Aile sağlığı elemanı, sağlık hizmetleri, iş doyumu

Sorumlu yazar: Hasan Durmuş, MD., Halk Sağlığı Uzmanı, Şanlıurfa Siverek Toplum Sağlığı Merkezi; Tlf: +90 (414) 318 7593; Cep telefonu: +90 (544) 370 6917; E-posta: drhasandurmus@gmail.com

\section{Copyright holder Turkish Journal of Public Health}

This work is licensed under a Creative Commons Attribution-NonCommercial 4.0 International License. $(\mathrm{cc}) \mathrm{EY}-\mathrm{NC}$ 


\title{
Job satisfaction and the effecting factors among family health nurses in Şanlıurfa
}

\begin{abstract}
Aims: The aim of this study was to determine the demographic qualities of Şanlıurfa family health center nurses, the qualities of the population they served, their thoughts about their professions, their job satisfaction and the factors which affected their job satisfaction. Methods: This study was a cross-sectional study of family health nurses working in Sanliurfa. According to the calculated sample size, 150 family health nurses were randomly selected from an equal distribution of central and rural areas in city. The questionnaire measured the sociodemographic and occupational characteristics of family health nurses, and utilised the Minnesota job satisfaction scale. Results: Research was completed on 125 (83.3\%) of the family health nurses. $87.2 \%$ of the family health nurses in the study were women, and $28.8 \%$ worked in the rural areas of the city. The mean general, internal and external job satisfaction scores of family health nurses were $3.05 \pm 0.74,2.79 \pm 0.79$ and $3.23 \pm 0.79$ respectively. $26.4 \%$ of the family health nurses had high job satisfaction. Variables that increased the job satisfaction of family health nurses included planning to work permanently in family health centers [OR: 3.25 (1.188.96)], and being generally pleased with their jobs [OR: 4.46 (1.17-16.93)]. Conclusion: Family health nurses have low job satisfaction. Family health nurses also have an important status in primary health care. Making arrangements that will increase job satisfaction will also increase the quality of healthcare services.
\end{abstract}

Keywords: Family health nurse, health services, job satisfaction

\section{Giriş}

Gelişen ve değișen dünyada demografik değişiklikler, hastaların ihtiyaçlarıyla beklentileri dikkate alınarak, sağlık hizmetinde yeni düzenlemeler gerçekleşmektedir. ${ }^{1}$ Sağlık hizmetlerinin ulaşlabilir ve herkes tarafindan faydalanılabilir olmasını sağlamanın yolu birinci basamak sağlık hizmetlerini güçlendirmektir. Aile hekimliği sistemi birinci basamak sağlık hizmetleri sunmada, kişileri ve aileleri, yaşadıkları çevreyle birlikte değerlendirerek koruyucu ve tedavi edici hizmetleri bir bütün halinde veren bir sistemdir. ${ }^{2}$ Ülkemizde de birinci basamak sağllk hizmetlerini güçlendirmek için 2004 yılında çıkarılan kanun ile Türkiye'de "Aile Hekimliği Modeli'ne geçiş yapılmıştır. ${ }^{3}$

Etkili bir sağlı hizmeti sunabilmek için en önemli güç insan gücüdür. Avrupa bölgesinin değerlendirildiği bir çalışmada Türkiye'nin birinci basamak sağlık hizmetlerinin yapısal yönü orta ve uygulama yönü zayıf bulunmuştur. ${ }^{4}$ Sağlık insan gücü bakımından Türkiye'nin yetersiz durumda olduğu, doktor ve hemşire sayısının gelişmiş ülkelerin gerisinde olduğu bilinen bir gerçektir. ${ }^{5} \mathrm{Bu}$ durum tüm sağlık sektörlerinde olduğu gibi birinci basamak sağlık hizmeti veren birimlerdeki doktor ve yardımcı sağlık personelinin iş yükünü artırmaktadır. Diğer taraftan sağlık göstergelerinin düşük, doğurganlık hızının en yüksek il olduğu Şanlıurfa'da koruyucu sağlık hizmetinin merkezinde olan aile sağlığı elemanlarının (ASE) iş yükünün fazla olması öngörülmelidir. ${ }^{6}$

İş doyumu, çalışanın kendi işinden duyduğu hoşnutluk, kendisini ve işini değerlendirmesi sonucu ulaştığı olumlu duygusal durum olarak tanımlanmaktadır. ${ }^{7}$ İlk kez 1920'lerde ortaya çıkan ve özellikle son yıllarda davranış bilimcilerin önem verdiği konulardan birisi olan iş doyumu, bireylerin fiziksel ve ruhsal sağlıklarını doğrudan etkilediği gibi iş hayatında etkinlik ve verimliliğin artmasında olumlu etkileri vardır. Ayrıca iş doyumunun yetersiz olması, stres ve grup uyumu sorunları gibi olumsuzluklara neden olacağından bu kavramın iş hayatındaki önemini arttırmaktadır. En önemli iş doyumsuzluk göstergeleri; verim 
düşüklüğü, şikâyet ve yakınmaların artması, işe devamsızlık ve gecikme oranının yükselmesi gibi durumlardır.8,9 Düşük iş doyumu düzeyleri veya işten memnun olmama çalışanların işi yavaşlatmasına, konsantrasyon eksikliğine, iş disipliniyle ilgili problemlere ve hata yapma ihtimalinin artmasina neden olabilmektedir ${ }^{10}$. Bu çalışmada Şanlıurfa'da hizmet veren ASE'lerin demografik özellikleri, hizmet sundukları nüfusun özellikleri, meslekleriyle ilgili düşünceleri, iş doyumları ve iş doyumu üzerine etkili olabilecek değişkenlerin tespiti amaçlanmıştır.

\section{Gereç ve Yöntem}

Çalıșma, Aralık 2016-Kasım 2017 tarihleri arasında Şanlıurfa'da görev yapan 520 ASE üzerinde yapılmış kesitsel tipte bir araştırmadır. Yüksek iş doyumuna sahip olma slklığ $1 \% 15, \mathrm{t}=1.96, \mathrm{~d}=0.05$ alınarak \%90 güven düzeyinde 110 kişiye ulaşılması $^{11}$ ve ilçe dağılımı ve kır-kent hizmet sunumu durumu göz önünde bulundurularak ağırlıklandırıldı ve rasgele seçilen 150 ASE'ye ulaşılması hedeflendi.

Çalışmada ASE'lere anket internet aracılığıyla ulaştırıldı. Geri dönüşümünün olmadığı ASE'lere iki kez hatırlatma epostasindan sonra hatırlatma telefon aramaları yapılıp, anketi doldurmaları istendi. 25 ASE çalışmayı katılmayı reddetti.

ASE'ler için hazırlanan anket formu, bireylerin sosyodemografik özellikleri, meslek ve çalıșılan birimiyle ilgili bazı özellikleri (meslekte çalışma süresi, son birimde çalışılan süre, kamuda kadrolu bulunma durumu, gelecek hakkında düşünce, çalışılan birimin yoğunluk derecesi, birimin gebe-bebek-mobil nüfusları, ASM personel sayı, ASM fiziksel yeterlilik vb.) ve Minnesota İş Doyum Ölçeği (MIDÖ) değişkenlerini içermekteydi.

İş doyumu değerlendirmesi için MIDÖ kullanıldı. Sağlık çalışanlarının iş doyumlarını ölçmek için en fazla tercih edilen ölçeklerden biri olan MİDÖ'nün özgün versiyonu, 1967 yılında Weiss ve arkadaşları tarafından geliştirilmiş olup, Türkçe versiyonu için güvenirlik ve geçerlilik çalışması 1985 yılında Baycan tarafından yapılmıștır. ${ }^{12}$ MIDÖ, 1-5 arasında puanlanan beșli Likert tipi bir ölçektir MIDÖ, içsel 12 madde (kişisel faktörlere bağlı iş doyumu), dişsal 8 maddeden (çevresel faktörlere bağlı iş doyumu), toplamda 20 maddeden oluşur. Genel iş doyumu puanı 20 parametreden elde edilen toplam puanın 20'ye bölünmesiyle içsel doyum puanı içsel faktörleri oluşturan parametrelerden elde edilen toplam puanın 12'ye bölünmesiyle dışsal doyum puanı ise dışsal faktörleri oluşturan parametrelerden elde edilen toplam puanın 8'e bölünmesiyle elde edilmektedir. Tüm puan ortalamaları 1 ile 5 arasında bir değer olarak hesaplanmaktadır. Yüzdelik değer olarak $\% 75$ ve üzeri ise yüksek iş doyumunu ifade eder. ${ }^{13}$

Çalışma için gerekli izinler, Şanlıurfa Halk Sağlığı Müdürlüğü ve Harran Üniversitesi Tıp Fakültesi Etik Kurulundan alındı. Araștırma Helsinki Deklarasyonu prensiplerine uygun olarak yapıldı ve çalışmaya katılan bireylerden "bilgilendirilmiş olur (rıza)" alındı. Çalışma verileri, SPSS 20.0 versiyonda analiz edildi. Grupların sıklı değerlerinin karşılaştırılmasında ortalama, standart sapma, yüzdeler ve Ki-Kare testi kullanıldı.

Çok değişkenli logistik regresyon analizleri için bağımlı değişken, yüksek iş doyumuna sahip olma durumu olarak alındı. Çok değişkenli analizde, tek değişkenli analizlerde $\mathrm{p}<0.10$ 'dan düşük anlamlılık veren değişkenlerle model oluşturuldu.

\section{Bulgular}

Çalışmaya katılan ASE'lerin \%87.2'si kadın (n=106), \%28.8'i (n=36) kırsalda hizmet vermektedir. Yaş ortalaması 29.16. \pm 4.43 olup; meslekte $7.35 \pm 4.25$ ylldır çalışmaktadırlar ve ASE olarak hizmet ortalama süresi $3.59 \pm 2.04$ yıldır. ASE'lerin hizmet verdikleri nüfusun demografik özellikleri Tablo 1'de gösterilmiştir.

ASE'lerin \%16'sı (n=20) kamu dışı sağllk personelidir. Personelin \%92.8'i (n=116) çalıştıkları birimin yoğun olduğunu belirtmiş olup meslekleriyle ilgili düşünceleri Tablo 2'de görülmektedir. 
Tablo 1. Aile sağlığı elemanlarının bazı mesleki özellikleri ve hizmet verdiği nüfusun demografik özellikleri

\begin{tabular}{lcc}
\hline Özellikler & Ortalama (士SD) & Ortanca (Min - Max) \\
\hline Gebe Sayısı & $62.5 \pm 22.0$ & $60(11-110)$ \\
Bebek Sayısı & $130.5 \pm 151.6$ & $115.0(30-1680)$ \\
Mobil Nüfus & $1064 \pm 1274$ & $479(0-4200)$ \\
Toplam Nüfus & $3811 \pm 881$ & $3900(400-10676)$ \\
\hline
\end{tabular}

ASE'lerin genel, içsel ve dışsal iş doyum puan ortalamaları sirasiyla 3.05 $\pm 0.74, \quad 2.79 \pm 0.79$ ve $3.23 \pm 0.79$ olarak bulundu. ASE'lerin \%26.4'ü (n:33) yüksek iş doyumuna sahipken, \%73.6 (n:92) ortadüşük iş duyumuna sahipdi. ASE'lerin yüksek iş doyumu üzerine etkili olabilecek değişkenler Tablo 3'de verilmiştir.

\section{Tartışma}

Çalışma sonucunda aile sağlığı elemanlarının yaklaşık 1/4'ünde yüksek iş doyumu olduğu görülmüştür. Genel iş doyumu puan ortalaması $3.05( \pm 0.74)$ olup, Malatya'da aile sağlığı elemanları üzerinde yapılan benzer bir çalışmada iş doyumu puan ortalaması aile sağlığı elamanları için $3.13 \pm 0.59$ olarak bulunurken, İzmir'de hastanede çalışan hemşirelerde yapılan bir çalıșmada, hemşirelerin iş doyumu puan ortalaması $\quad 3.21 \pm 0.03 \quad$ olarak bulunmuştur. ${ }^{14,15}$ Türkiye'de yapılan çalışmalar incelendiğinde iş doyumu göstergesi olarak MİDÖ puan ortalaması gösterilmiş, kategorik olarak sınıflama yapılmamıştır. 14,16,17 Bizim çalışmamızda iş doyumu kategorik olarak değerlendirilmiş, yüksek ve orta-düşük iş doyumuna etki eden faktörler bu yönüyle incelenmiştir. İkili karşılaştırma sonucunda anlamlı olduğu düşünülen değişkenlerin çoklu analize alınarak orta-düşük iş doyumuna etkileri irdelenmiştir. Çoklu analiz sonucunda bulunduğu aile sağlığı merkezinde kalıcı olarak çalışmayı düşünmeyenlerin ortadüşük iş doyumu 3.25(1.18-8.96) kat ve genel olarak işinden memnun olmayanların orta-düşük iş doyumu 4.46 (1.17-16.93) kat fazla bulunmuştur.
Mesleğini isteyerek seçenlerde iş doyumu daha yüksek bulunmuştur. Hemşireler üzerinde yapılan bir çalışmada mesleğini severek yapmanın iş doyumunu olumlu etkilediği gösterilmiştir. ${ }^{18}$ Yine sevdiği mesleği tercih etmenin sorgulandığ 1 araştırmalarda, mesleğini kendi veya severek tercih eden hemşirelerin iş doyumu farklı bir nedenle mesleği tercih edenlere göre yüksek bulunmuştur. ${ }^{14,19}$ Mesleğini isteyerek seçenlerin işini severek yapacakları düşünülüp iş doyumunu etkileyen önemli etkenlerden olduğu kabul edilebilir.

ASE'larını kapsayan bir çalıșmada iși bırakmayı düşünenlerin iş doyumu puanı daha düşük bulunmuştur.14 Zhang ve arkadaşları tarafından birinci basamak sağlık çalışanlarının iş doyumunun araştırıldığı sistematik derlemenin sonuçlarına göre mesleki gelişim için firsatların sunulması ve maddi imkânlar en önemli iş memnuniyet belirleyicileri olarak tespit edilmiştir. ${ }^{20}$ Bizim çalışmamızda da çoklu analizle aile sağlığı merkezinde kalıcı olarak çalışmayı düşünmeyenlerde ortadüşük iş doyumu 3.25(1.18-8.96) kat fazla bulunmuştur. ASE'lerin işlerinde ilerleyemeyeceklerini hissetmeleri bu durumun nedeni olabilir.

Çalışmamızda katılımcıların \%92.8'i işin yoğun olduğunu, 2/3'ü personel sayısının yetersiz olduğunu belirtmiş ve personel sayısı yetersiz diyenlerde ortadüşük iş doyumu daha fazla görülmüştür. Baysal ve arkadaşları tarafından yapılan bir çalışmada ASE'lerin \%88.3'ü sağlık elemanı sayısının yetersiz olduğunu ve $\% 85^{\prime} i$ iș yükünün fazla olduğunu belirtmiștir. ${ }^{20}$ 
Tablo 2. Aile sağlığı elemanlarının meslekleri ile ilgili düşünceleri

\begin{tabular}{|c|c|c|c|c|c|c|c|}
\hline \multirow[b]{2}{*}{ Durum ve düşünceler } & & \multicolumn{2}{|c|}{$\begin{array}{l}\text { Orta-düşük } \\
\text { iş doyumu }\end{array}$} & \multicolumn{2}{|c|}{$\begin{array}{c}\text { Yüksek } \\
\text { iş doyumu }\end{array}$} & \multicolumn{2}{|c|}{ Toplam } \\
\hline & & $\mathrm{n}$ & $\%$ & $\mathrm{n}$ & $\%$ & $\mathrm{~N}$ & $\%$ \\
\hline \multirow{2}{*}{$\begin{array}{l}\text { Görevinizle ilgili özel bir eğitim (kurs, seminer vb.) } \\
\text { aldınız mı? }\end{array}$} & Evet & 61 & 74.4 & 21 & 25.6 & 82 & 65.6 \\
\hline & Hayır & 31 & 72.1 & 12 & 27.9 & 43 & 34.4 \\
\hline \multirow{2}{*}{ Mesleğinizi isteyerek mi seçtiniz?* } & Evet & 73 & 70.2 & 31 & 29.8 & 104 & 83.2 \\
\hline & Hayır & 19 & 90.5 & 2 & 9.5 & 21 & 16.8 \\
\hline \multirow{2}{*}{ Kazandığınız ücret sizce yeterli mi? } & Evet & 17 & 65.4 & 9 & 34.6 & 26 & 20.8 \\
\hline & Hayır & 75 & 75.8 & 24 & 24.2 & 99 & 79.2 \\
\hline \multirow{2}{*}{$\begin{array}{l}\text { Son } 1 \text { yıl içinde ASM'nizdeki boş pozisyonlar nedeni } \\
\text { ile birden fazla birime baktınız mı? }\end{array}$} & Hayır & 41 & 71.9 & 16 & 28.1 & 57 & 45.6 \\
\hline & Evet & 51 & 75.0 & 17 & 25.0 & 68 & 54.4 \\
\hline \multirow{2}{*}{$\begin{array}{l}\text { Aile sağlığı elemanı olarak mesleğinizin dışında işler } \\
\text { yaptığınızı düşünüyor musunuz? }\end{array}$} & Hayır & 14 & 60.9 & 9 & 39.1 & 23 & 18.4 \\
\hline & Evet & 78 & 76.5 & 24 & 23.5 & 102 & 81.6 \\
\hline \multirow{2}{*}{$\begin{array}{l}\text { Aile Hekimliği Sisteminin sağlık hizmetleri } \\
\text { etkinliliğini arttırdığını düşünüyor musunuz?** }\end{array}$} & Evet & 63 & 66.3 & 32 & 33.7 & 95 & 76.0 \\
\hline & Hayır & 29 & 96.7 & 1 & 3.3 & 30 & 24.0 \\
\hline \multirow{2}{*}{$\begin{array}{l}\text { ASM'de kalıcı olarak çalışmayı düşünüyor } \\
\text { musunuz?** }\end{array}$} & Evet & 27 & 55.1 & 22 & 44.9 & 49 & 39.2 \\
\hline & Hayır & 65 & 85.5 & 11 & 14.5 & 76 & 60.8 \\
\hline \multirow{2}{*}{ Genel olarak ișinizden memnun musunuz?** } & Evet & 54 & 66.7 & 27 & 33.3 & 81 & 64.8 \\
\hline & Hayır & 38 & 86.4 & 6 & 13.6 & 44 & 35.2 \\
\hline \multirow{2}{*}{$\begin{array}{l}\text { Aile Sağlığı Elemanı olmak ile ilgili endişeleriniz, } \\
\text { gelecek kaygılarınız var mı** }\end{array}$} & Hayır & 6 & 40.0 & 9 & 60.0 & 15 & 12.0 \\
\hline & Evet & 86 & 78.2 & 24 & 21.8 & 110 & 88.0 \\
\hline \multirow{2}{*}{$\begin{array}{l}\text { Hizmetlerinizden nüfusunuzun memnun olduğunu } \\
\text { düşünüyor musunuz?* }\end{array}$} & Evet & 78 & 70.9 & 32 & 29.1 & 110 & 88.0 \\
\hline & Hayır & 14 & 93.3 & 1 & 6.7 & 15 & 12.0 \\
\hline \multirow{2}{*}{ Sizce çalıştığınız birim yoğun mu? } & Hayır & 5 & 55.6 & 4 & 44.4 & 9 & 7.2 \\
\hline & Evet & 87 & 75.0 & 29 & 25.0 & 116 & 92.8 \\
\hline \multirow{2}{*}{$\begin{array}{l}\text { ASM bünyesinde çalışan personel sayınız sizce } \\
\text { yeterli mi?** }\end{array}$} & Evet & 25 & 59.5 & 17 & 40.5 & 42 & 33.6 \\
\hline & Hayır & 67 & 80.7 & 16 & 19.3 & 83 & 66.4 \\
\hline \multirow{2}{*}{$\begin{array}{l}\text { Çalışmakta olduğunuz ASM'nin fiziksel imkânları } \\
\text { yeterli mi?** }\end{array}$} & Evet & 18 & 52.9 & 16 & 47.1 & 34 & 27.2 \\
\hline & Hayır & 74 & 81.3 & 17 & 18.7 & 91 & 72.8 \\
\hline \multirow{2}{*}{$\begin{array}{l}\text { Çalışmakta olduğunuz ASM'nin de sarf malzeme } \\
\text { eksikliği yaşıyor musunuz? }\end{array}$} & Evet & 46 & 76.7 & 14 & 23.3 & 60 & 48.0 \\
\hline & Hayır & 46 & 70.8 & 19 & 29.2 & 65 & 52.0 \\
\hline Toplam & & 92 & 73.6 & 33 & 26.4 & 125 & 100.0 \\
\hline
\end{tabular}

Literatür incelendiğinde iș yükü fazla olan hemşirelerin iş doyumunun düşük olduğu görülmektedir. ${ }^{18,22,23}$ Shi ve arkadașları tarafından yapılan bir çalıșmada iș yoğunluğunun iș doyumunu etkileyen ana değişken olduğu bildirilmiștir. ${ }^{23}$ Çalışmamızda iş yoğunluğu ile iş doyumu arasında bir ilişki bulunamadı. Bunun nedeni Şanlıurfa ilinin nüfus yapısı itibari ile birinci basamak sağlık hizmetlerinde iş yükü üst düzeyde olması olabilir.
Katılımcıların birim bașına düșen ortalama nüfus ve bebek sayısı sırasıyla $3811 \pm 881$ ve $130.6 \pm 151.7$ olup Türkiye'nin batı bölgesinde yapılmıș bir çalıșmada aile sağlığı hekimine düșen ortalama nüfus ve bebek sayıları sirasiyla $3486.6 \pm 465.9$ ve $47.1 \pm 18.2$ olarak belirlenmiștir. ${ }^{25}$ Özellikle ana çocuk sağlığı hizmetleri nüfusun yapısı itibari ile hizmet sunumunda geniş yer almaktadır. 
ASE'lerin 2/3'ünün işinden memnun olduğu görülmüș ve işinden memnun olma durumunun orta-düşük iş doyumuna sahip olmada en önemli etken olduğu, işinden memnun olmayanlarda orta-düşük iş doyumunun 4.46 (1.17-16.93) kat fazla olduğu belirlenmiştir. Hemşirelerin meslekten memnun olma durumu başka bir çalışmada \%68.1 ile bizim çalışmamıza benzer bulunmuştur ancak bu çalışma iş doyumuyla meslekten memnun olmayl birlikte değerlendirmemiștir. ${ }^{15}$ Aile hekimliği sisteminden memnun olma ile iş doyumunun değerlendirildiği bir çalışmada, sistemden memnun olanlarda iş doyumu puanı daha yüksek bulunmuștur.14 İș memnuniyetinin artışıyla birinci basamak sağlık hizmetinde kalitenin de artması beklenmektedir. ${ }^{26}$

Çalışmamızda ASE'lerin büyük çoğunluğu ASM’lerin fiziksel imkânlarını yetersiz bulmuş, orta-düşük iş doyumuna sahip olan ASE'ler fiziksel imkânları daha fazla yetersiz olarak değerlendirmiștir. Galeto ve arkadaşları tarafından yapılan çalışmada fiziki şartların iş doyumuna 4.61 kat etkili olduğu tespit edilmiştir. ${ }^{27}$

Şüphesiz ücret iş doyumunu etkileyen faktörlerden bir tanesidir, bizim çalışmamızda ücreti düşük bulanlarda ortadüşük iş doyumuna sahip olma daha yüksek olsa da istatistiksel olarak bir fark bulunmamakla birlikte katılımcların \%79.2'i kazandıkları ücretin yetersiz olduğunu düşünmektedir (Tablo 2). Malatya'da yapılan çalışmada ücretten memnun olanlarda iş doyumu puanı daha yüksek bulunmuştur. ${ }^{14}$ Farklı bir çalışmada aldığı ücreti yetersiz bulan ASE'lerin oranı \%84 olarak bildirilmiștir. ${ }^{28}$ Bir başka çalışmada ücret düşüklüğü nedeniyle memnuniyetsiz bildiren ASE'lerin oranı $\% 75.3^{\prime}$ tür. $^{21}$

Tablo 3. Aile sağlığı elemanlarında yüksek iş doyumu üzerine etkili olabilecek değişkenler ve çok değişkenli analiz sonuçları

\begin{tabular}{|c|c|c|}
\hline \multirow[t]{2}{*}{ Özellik } & \multicolumn{2}{|c|}{$\begin{array}{c}\text { Aile sağlığı elemanlarında } \\
\text { yüksek iş doyumu }\end{array}$} \\
\hline & OR & $\% 95 \mathrm{GA}$ \\
\hline Mesleğinizi isteyerek mi seçtiniz? (Referans: Evet) & 2.43 & $0.43-13.67$ \\
\hline $\begin{array}{l}\text { Aile Hekimliği Sisteminin sağllk hizmetleri etkinliliğini arttırdığını } \\
\text { düşünüyor musunuz? (Referans: Evet) }\end{array}$ & 6.35 & $0.77-52.34$ \\
\hline $\begin{array}{l}\text { ASM'de kalıcı olarak çalışmayı düşünüyor musunuz? } \\
\text { (Referans: Evet) }\end{array}$ & 3.25 & 1.18-8.96 \\
\hline Genel olarak işinizden memnun musunuz? (Referans: Evet) & 4.46 & 1.17-16.93 \\
\hline $\begin{array}{l}\text { Aile Sağlığı Elemanı olmak ile ilgili endişeleriniz, gelecek } \\
\text { kaygılarınız var mı? (Referans: Evet) }\end{array}$ & 1.71 & $0.17-16.28$ \\
\hline $\begin{array}{l}\text { Hizmetlerinizden nüfusunuzun memnun olduğunu düşünüyor } \\
\text { musunuz? (Referans: Evet) }\end{array}$ & 2.07 & $0.73-5.88$ \\
\hline $\begin{array}{l}\text { ASM bünyesinde çalışan personel sayınız sizce yeterli mi? } \\
\text { (Referans: Evet) }\end{array}$ & 1.99 & $0.70-5.68$ \\
\hline $\begin{array}{l}\text { Çalışmakta olduğunuz ASM'nin fiziksel imkânları yeterli mi? } \\
\text { (Referans: Evet) }\end{array}$ & 1.07 & $0.32-3.64$ \\
\hline
\end{tabular}




\section{Sonuç}

Çalsșma sonucunda ASE'lerin yalnızca $1 / 4$ 'ünde yüksek iş doyumuna sahip olduğu, is doyumunu etkileyen en önemli iki faktörün ișinden memnun olma ve aile sağlığı merkezinde kalıcı olarak çalışmayı düşünme olduğu belirlenmiştir. Şanlıurfa'da gerek bebek sayısının çok olması, gerek mobil nüfus oranlarının fazla olması nedeniyle birinci basamağa daha çok iș düşmekte ve aile sağlığı elemanlarının iş yükü artmaktadır. Aile hekimliği birimlerinin artırılarak birim bașına düșen nüfus, gebe ve çocuk sayısının azaltılması, personel üzerindeki iş yükü baskısını azaltacaktır. Ayrıca bölgesel olarak aile sağlığı merkezlerinde çalışan yardımcı personel sayısının nüfus yapısına göre planlanması, gerekirse kadın, bebek veya gebe sayısına orantılı olarak belirlenmesi, aile sağlı̆̆ merkezlerinde çalışan personelin iş doyumu artırmanın yanında sağlık hizmetleri sunumunun kalitesini de artıracaktır. Gelecek kaygısıyla kalıcı olarak aile sağlığı merkezinde çalışmayı düşünmeyen personelin iş doyumu da düşmektedir. Sağlık personelinin gelecek kaygısının nedenleri ve kalıcı olarak çalıșmak istememelerinin nedenlerinin araştırılması için yeni araştırmalar planlanmalıdır.

Sınırlılıklar ve güçlü yönleri: Çalışma bölgesel bir alanda yapıldığı için örneklem sayısı küçük kalmış olabilir. Nüfus yapısı olarak doğurganlığın yüksek olduğu bir bölgede birinci basamak insan gücünün değerlendirilmesi açısından önemli bir çalışma olarak birinci basamak sağlık hizmetlerinin gelecek planlamasında yol gösterici olacağı düşünülmektedir.

Çıkar çatışması: Herhangi bir çıkar çatışması yoktur.

Yazarların katkıları: Mehmet Enes Gökler, Planlama, Veri toplama, Yazma, Değerlendirme; Hasan Durmuş, yazma, değerlendirme.

\section{Kaynaklar}

1. Ylkılkan H, Aypak C, Görpelioğlu S. Aile hekimliği uzmanı olmak için öğrencilerin motivasyonları ve Aile hekimliği uzmanlarının iş doyumları: literatür taraması. TJFMPC 2012;6(2):36-41.

2. Akdağ R, Erkoç Y. Türkiye Sağlıkta Dönüşüm Programı Değerlendirme Raporu 2003-2011. TC Sağlık Bakanlığı, Ankara, 2012.

3. Akdağ R. Nereden Nereye: Türkiye'de Sağlıkta Dönüşüm Programı: Kasım 2002-Haziran 2007. Ankara: Sağlık Bakanlı̆̆ı, 2007.

4. Kringos DS. The importance of measuring and improving the strength of primary care in Europe: results of an international comparative study. Turk Aile Hek Derg 2013;17(4):165-179.

5. Akman M. Türkiye'de birinci basamağın gücü. Turk Aile Hek Derg 2014;18(2):70-78.

6. Doğum İstatistikleri, 2016. Türkiye İstatistik Kurumu. Available at: http://www.tuik.gov.tr/HbPrint.do?id=246 47. Accessed May 18, 2017.

7. Judge TA, Thoresen CJ, Bono JE, Patton GK. The job satisfaction-job performance relationship: A qualitative and quantitative review. Psychological bulletin 2001;127(3):376.

8. Faragher EB, Cass M, Cooper CL. The relationship between job satisfaction and health: a meta-analysis. In From Stress to Wellbeing Volume 1. Palgrave Macmillan, London, 2013, pp. 254-271.

9. Spector PE. Job satisfaction: Application, assessment, causes, and consequences (Vol. 3). Sage publications. 1997. 
10. Barling J, Kelloway EK, Iverson RD. High-quality work, job satisfaction, and occupational injuries. Journal of applied psychology 2003;88(2):276.

11. Tözün M, Çulhacı A, Ünsal A. Aile hekimliği sisteminde birinci basamak sağlık kurumlarında çalışan hekimlerin iş doyumu. TAF Preventive Medicine Bulletin 2008;7(5): 377-384.

12. Weiss DJ, Dawis RV, England GW, Lofquist LH. Manual for the Minnesota Satisfaction Questionnaire. Minneapolis, MN: University of Minnesota Industrial Relations Center, 1967.

13. Sevimli F, Iscan ÖF. Bireysel ve is ortamına ait etkenler açısından iş doyumu. Ege Academic Review 2005; 5(1): 55-64.

14.Tekin Ç, Bozkır Ç, Sazak Y, Özer A. Malatya il merkezinde çalışan aile hekimleri ile aile sağlığı elemanlarının, aile hekimliği uygulaması hakkındaki görüşleri, iş doyumu düzeyleri ve etkileyen faktörler. Firat Tıp Dergisi 2014;19(3):135-139.

15. Büyükbayram A, Gürkan A. Hemşirelerin iş doyumunda duygusal zekânın rolü. J Psy Nurs 2014;5(1):41-48.

16. Çimen M, Şahin İ. Bir kurumda çalışan sağlık personelinin iş doyumu düzeyinin belirlenmesi. Hacettepe Sağlı İdaresi Dergisi 2000;5(4):53-67.

17. Tambağ H, Can R, Kahraman Y, Şahpolat M. Hemşirelerin çalışma ortamlarının iş doyumu üzerine etkisi. Bakırköy Tıp Dergisi 2015;11(4):143-149.

18. Durmuş $\mathrm{S}$, Günay $\mathrm{O}$. Hemşirelerde iş doyumu ve anksiyete düzeyini etkileyen faktörler. Erciyes Med J 2007;29(2):139146.

19. Yılmazel G. Hemşirelerde psikolojik yıldırma, iş doyumu ve etkileyen faktörler.
Turkiye Klinikleri J Nurs Sci 2013;5(2):5563.

20. Zhang M, Yang R, Wang W, Gillespie J, Clarke S, Yan F. Job satisfaction of urban community health workers after the 2009 healthcare reform in China: a systematic review. Int J Qual Health Care 2016;28(1):14-21.

21. Baysal HY, Hacialioğlu N, Yıldız E, Öztürk S. Birinci basamakta görev yapan sağlık çalışanlarının aile hekimliği modelinden memnuniyet durumları ve bu konudaki görüşleri. ERÜ Sağlık Bilimleri Fakültesi Dergisi 2014;2(1):22-29.

22. Aksoy NM, Polat C. Akdeniz bölgesindeki bir ilde üç farklı hastanenin cerrahi birimlerinde çalıșan hemșirelerin iș doyumu ve etkileyen faktörler. HEAD 2013;10(2):45-53.

23. Zangaro GA, Soeken KL. A meta-analysis of studies of nurses' job satisfaction. Res Nurs Health 2007;30(4):445-458.

24. Shi L, Song K, Rane S, Sun X, Li H, Meng Q. Factors associated with job satisfaction by Chinese primary care providers. Prim Health Care Res Dev 2014;15(1):46-57.

25. Tuncal AN, Köroğlu G, Atasoylu G, Sertel M, Tay Z. Manisa ilinde aile hekimlerinin 2011 yılındaki iş yükü ve insan gücünün değerlendirilmesi. Türkiye Aile Hek Derg 2014;18(1):5-15.

26. Mohr DC, Young GJ, Meterko M, Stolzmann KL, White B. Job satisfaction of primary care team members and quality of care. Am J Med Qual 2011;26(1):18-25.

27. Geleto A, Baraki N, Atomsa GE, Dessie Y. Job satisfaction and associated factors among health care providers at public health institutions in Harari region, 
eastern Ethiopia: a cross-sectional study. BMC Res Notes 2015;8:394.

28. Doğan N, Şensoy N, Mardin E, Uçur İ, Özbalcı T. Aile sağlığı merkezinde çalışan sağlık personelinin aile hekimliğine bakış açıları. J Clin Analyt Med 2013; 4: 112-115. 